\title{
Effect of Pelvic Control Exercises on Pelvic Asymmetry and Gait in Stroke Patients
}

\author{
MOHAMED H. MARZOUK, M.Sc.*; MOHAMED S. EL-TAMAWY, M.D.**; MOSHERA H. DARWISH, Ph.D.*; \\ HEBA A. KHALIFA, Ph.D.* and ISLAM M. AL-AZAB, Ph.D.* \\ The Departments of Neuromuscular Disorder, Faculty of Physical Therapy* and Neurology, Faculty of Medicine**, \\ Cairo University
}

\begin{abstract}
Background: Gait abnormality is one of the most common impairments after stroke. Pelvic control exercises may affect gait and pelvic asymmetry in stroke patients.

Aim of Study: To determine the effect of pelvic control exercises on pelvic asymmetry and gait in stroke patients.

Patients and Methods: Thirty male ischemic stroke patients represented the study. Their age ranged from 45 to 60 years. The patients were assigned into two equal groups; control group (GA) treated by selected physical therapy program and study group while (GB) treated by the same program in addition to pelvic control exercises. The spatiotemporal gait parameters were assessed by Biodex gait trainer 2TM system. Sagittal pelvic tilt angles were measured by Palmation meter (PALM) inclinometer from standing position.

Results: Post-treatment there were a significant improvement in all measured variables except the average step length of the non-affected side in both groups. Comparison between both groups revealed a significant decrease of the anterior pelvic tilting angles on both sides, the average step length of the affected side and the percent of time spent on the non affected foot with significant increase of the percent of time spent on the affected foot in favor to (GII) $(p<0.05)$. No significant difference of the average walking speed and average step length of the non affected side was detected between both groups.

Conclusion: Pelvic control exercises have a positive effect on the pelvic asymmetry and consequently on gait performance in stroke patients.
\end{abstract}

Key Words: Pelvic control exercises - Pelvic tilt angle$P A L M-$ Biodex gait trainer.

\section{Introduction}

HEMIPLEGIA is one of the most common impairments after stroke. It contributes significantly to reduce gait performance [1]. Gait in patients

Correspondence to: Dr. Mohamed H. Marzouk, E-Mail: mohamedhelayel1990@.gmail.com after stroke is characterized by reduced preferred walking speed, cadence, stride length and symmetry, prolonged stance duration on the non-paretic side and decreased on the paretic side [2]. Stroke patients have difficulty in maintaining the spine upright, rotating the trunk, moving the pelvis forward and backward during transfer of weight, or maintaining balance response [3]

Altered pelvic alignment and asymmetrical weight bearing on lower limbs are the most common findings observed after stroke. Ability to transfer weight on paralyzed lower extremity is a prerequisite for functional mobility skills [4]. The forward and backward pelvic tilts are frequently affected in stroke patients. They have a more forward-leaning posture with an anteriorly tilted pelvis in standing ability [5]. The altered recruitment of hip abductors and extensors on the most affected leg influences the pelvic stability resulting in more lateral and anterior pelvic tilt in the frontal and sagittal plane; respectively [6]. Pelvic displacement triggers difficulty in maintaining balance and normal gait and restricts social participation [7].

Pelvic exercises improve the pelvic motion and locomotor. It is very important in gait economy [8]. Pelvic tilting exercises affect the asymmetric pelvis of stroke patients, enhance balance and have an influence on circumduction gait pattern of lower limb and locomotor performance $[\mathbf{9 , 1 0 ]}$. Pelvic stabilization exercises simultaneously activate lower trunk and hip muscles. They provide core

\footnotetext{
Abbreviations:

PALM : Palpation Meter Inclinometer.

MAS : Modified Ashworth Scale.

BMI : Body Mass Index.

CT : Computed Topography.

MRI : Magnetic Reasoning Imaging.
} 
stability and help to attain proper postures of the lumbar and pelvic region [11].

\section{Aim of this work:}

The aim of the present study is to determine the effect of pelvic control exercises on pelvic asymmetry and its consequence on gait performance in patients with stroke.

\section{Patients and Methods}

Thirty male ischemic Egyptian stroke patients participated in this study. They were recruited from Outpatient Clinic of Faculty of Physical Therapy, Cairo University and from Kasr El-Ainy Hospital, Faculty of Medicine, Cairo University during 2017. The patients were diagnosed by a neurologist and the diagnosis was confirmed by CT scan and/or MRI. Patients' age ranged from 45 to 60 years with BMI less $30 \mathrm{~kg} / \mathrm{m}^{2}$ and duration of stroke ranged from six months to 18 months. All patients were able to walk independently with or without assistive devices. The degree of spasticity of paretic lower limb muscles ranged from $(1: 1+)$ according to the Modified Ashworth Scale (MAS).

Patients with other neurological diseases, hemorrhagic stroke, significant musculoskeletal abnormalities for both lower limbs, contracture, deformities, cardiovascular or pulmonary diseases, cognitive impairments, Pusher syndrome, visual or auditory impairment were excluded.

The patients signed a written consent form. The study protocol was approved by the Ethical Committee of Faculty of Physical Therapy, Cairo University, Egypt. All patients were subjected to a full clinical neurological assessment.

The patients were assigned into two equal groups control group (GA) and study group (GB). Both groups were matched in the general characteristics including age, height and weight, body mass index and duration of illness $(p>0.05)$. The control group (GA) was treated by selected physical therapy program consisted of stretching exercises, facilitation of the weak muscles, strengthening exercises, proprioceptive neuromuscular facilitation and gait training, three sessions per week day after day for successive six weeks. Duration of each session ranged from 25-30 minutes according to the ability of each patient. The study group (GB) was treated by the same program in addition to pelvic control exercises for $40 \mathrm{~min}$ included pelvic tilting exercises and pelvic stabilization exercises from different positions. Pelvic tilting exercises included; anterior, posterior and lateral pelvic tilting from sitting, sit to standing and pelvic rotation on a therapeutic ball. Pelvic stabilization exercises included; weight shifting on the affected limb from standing, ball bridging, planking and stabilizing reversals exercises.

Spatiotemporal gait parameters were assessed pre and post treatment by Biodex gait trainer 2TM (Model 950-380, software Version 2.6x, New York). It is a special treadmill designed to monitor and record gait pattern. The patients were instructed to stand on trainer holding on rails and to bull the red safety key if they felt uncomfortable or losing balance. Patient's data (age, weight and height) were delivered to the machine to calculate the personal data for each patient. Speed was adjusted according to the patient tolerance. Patient was asked to walk with the regular walking pattern on the trainer for three minutes. The instrument measures walking speed $(\mathrm{m} / \mathrm{sec})$, average step length (m) of the affected and non affected side and time on each foot (recorded as a percent of gait cycle). Three trials were done and the mean was calculated.

Anterior and posterior pelvic tilting angles were measured pre and post treatment by the palpation meter (PALM) inclinometer (PALM device, Performance Attainment Associates, St. Paul, MN, USA) [11]. It consists of two caliper arms and an inclinometer. The inclinometer is a semi-circular arc with one degree gradation ranging from 0 to 30 degrees on either side of the midline. The caliper arms are designed for detect palpation of the bony landmarks. Pelvic tilting angles were measured on each side of the pelvis from standing position [13] Patient was asked to stand in relaxed position with bare feet and both legs at the same level. No specific instructions were provided to the patients regarding posture in order that measurements during a regular standing position could be recorded. The anterior superior iliac spine and the posterior superior iliac spine were palpated. The caliper tips are held with the fingers against bony prominence on the patient's body and the inclinometer displays the pelvic tilting angle in degrees. The angle is formed by a line from the anterior superior iliac spine to the posterior superior iliac spine relative to the horizontal plane [14]. Three measurements were recorded and the mean value was calculated.

\section{Statistical analysis:}

The data were analyzed using SPSS software (Version 16.0; SPSS, Chicago, IL, USA), and the demographic characteristics were reported with descriptive statistics. The obtained data were collected and statistically analyzed using the arithmetic mean and their standard deviation. Paired $t$-test was used for comparison of means pre and post- 
treatment within each group. Unpaired $t$-test for comparison of means pre and post-treatment of two independent groups. A $p$-value $<0.05$ was considered a statistically significant, and a $p$-value of $<0.001$ as highly statistically significant [15]

\section{Results}

Comparison of the mean values of all variables (anterior pelvic tilting angles, average step length, average walking speed and time on each foot) pre and post-treatment in each group revealed a statistical significant difference in all variables except for the average step length of the non-affected side. The results showed a significant decrease in the degree of pelvic tilting angles on the affected and non-affected sides, a significant decrease in the average step length of the affected side only and significant increase in the average walking speed pre and post-treatment in both groups. A significant increase in the percent of time spent on the affected side with significant decrease on the non-affected side pre and post-treatment in both groups $(p<0.01)$.

Comparison of the mean values of all variables post-treatment between both groups revealed a significant improvement in the study group compared to the control group in all variables $(p<0.05)$ except for the average walking speed and average step length of the non-affected side (Table 1).

Table (1): The mean values of all variables post treatment in both groups.

\begin{tabular}{|c|c|c|c|}
\hline \multirow[b]{2}{*}{ Variables } & \multicolumn{3}{|c|}{ Post-treatment } \\
\hline & $\begin{array}{l}\text { Control group } \\
\mathrm{X} \pm \mathrm{SD}\end{array}$ & $\begin{array}{c}\text { Study group } \\
\mathrm{X} \pm \mathrm{SD}\end{array}$ & $p$-value \\
\hline \multicolumn{4}{|l|}{ Anterior pelvic tilting angle $\left({ }^{o}\right)$ : } \\
\hline Affected & $10.93 \pm 1.907$ & $8.467 \pm 1.246$ & $0.0002 * *$ \\
\hline Non affected & $6.867 \pm 1.407$ & $5.533 \pm 0.9904$ & $0.0056^{*}$ \\
\hline \multicolumn{4}{|l|}{ Average step length $(\mathrm{m})$ : } \\
\hline Affected & $0.4827 \pm 0.04992$ & $0.446 \pm 0.04808$ & $0.0499 *$ \\
\hline Non affected & $0.3933 \pm 0.02743$ & $0.392 \pm 0.04296$ & 0.9200 \\
\hline Average walking speed $(\mathrm{m} / \mathrm{sec})$ & $0.64 \pm 0.02878$ & $0.6747 \pm 0.07708$ & 0.1139 \\
\hline \multicolumn{4}{|l|}{ Time on each foot $(\%)$ : } \\
\hline Affected & $45.07 \pm 1.668$ & $48.60 \pm 0.7368$ & $<0.0001 * *$ \\
\hline Non affected & $54.93 \pm 1.668$ & $51.40 \pm 0.7368$ & $<0.0001 * *$ \\
\hline $\begin{array}{l}\bar{x}: \text { Mean. } \\
\text { SD : Standard Deviation. }\end{array}$ & $p$ : Probability. & $\begin{array}{l}*: \text { Sign } \\
* *: \text { Sign }\end{array}$ & $\begin{array}{l}p<0.05 \\
\text { at } p<0.01\end{array}$ \\
\hline
\end{tabular}

\section{Discussion}

A significant improvement of the anterior pelvic tilting angles on both sides post-treatment was detected. Pelvic control exercises cause activation of the muscles around the hip, pelvic region and core muscles resulting in improvement the pelvic stability and postural alignment [12]. Core stability exercises can improve the activation and cooperative contractions of abdominal and multifidus muscles, facilitating the function and movement of the lower limbs [16].

Weakness of the hip abductors and extensors on the most affected leg influence the pelvic stability [6]. In the current study Pelvic tilting exercises increase the recruitment of hip abductors and extensors. This leads to increase in the pelvic stability. Pelvic tilting exercises and core stability training decrease lateral and anterior pelvic tilt that occur in the frontal and sagittal plane, respectively in stroke patients. It improves posterior pelvic tilt and center of gravity transfer during swing phase $[6,10,12,17]$.

A significant improvement of the average step length on the affected side post-treatment was detected. This improvement may be attributed to mechanical effect of pelvic control exercises. This caused reduction of the excessive pelvic elevation and anterior pelvic tilt angle during the stance and swing phase. These mechanical changes improve pelvic stability, reduce the hip hiking and reduce forward rotation of the pelvis on the affected side [17]. Improvement alignment of the pelvis would improve weight transference over the hemiplegic leg, resulting in improvement of the movement patterns both proximally at the hip and distally at the knee and foot in both the stance and the swing phases of the gait cycle. This result agreed with [18]

The results of the current study contradicted with Chung and colleagues [10]. The discrepancy 
between the present, Chung and colleagues may be due to they used small sample size, short duration of treatment and different characteristics of the sample (different degrees of spasticity).

Post-treatment results revealed a significant increase in the percent of time on the affected side and significant decrease on the non affected side in both groups indicating an improvement. Pelvic control exercises had a positive effect on increasing the weight bearing on the affected side by transferring weight from the unaffected limb to the hemiplegic limb. Increased weight bearing on the affected limb leading to more activation of the core, hip and leg muscles and. This leading to symmetrical weight distribution on both lower limbs, improvement of the pelvic alignment and side to side balance stability [6]

Pelvic tilting exercises in stroke patients improve gait pattern, promote perception of the lower limbs on the paretic side, increase the symmetry of pelvic alignment, stimulates normal movement, enhancing balance and gait ability and decreasing falling risk in stroke patients [10]. Core stabilization exercises increased posterior tilt of the pelvis and center of gravity transfer during the swing phase through core training. Core training improved the stability of the lower trunk and pelvis and increased the ability to static balance, dynamic balance, and weight support on the most affected side and contributed to a more stable gait [19]

\section{Conclusion:}

Pelvic control exercises had a positive effect on the pelvic asymmetry with improvement of gait performance in patients with stroke.

\section{Financial support and sponsorship: \\ Nil.}

\section{Conflicts of interest:}

There are no conflicts of interest.

\section{References}

1- FLANSBJER U.B., HOLMBÄCK A.M., DOWNHAM D., PATTEN C. and LEXELL J.: Reliability of gait performance tests in men and women with hemiparesis after stroke. J. Rehabil. Med., 37 (2): 75-82, 2005.

2- PLUMMER P., BEHRMAN A.L., DUNCAN P.W., SPIGEL P., SARACINO D., MARTIN J., et al.: Effects of stroke severity and training duration on locomotor recovery after stroke: A pilot study. Neurorehabil. Neural. Repair., 21 (2): 137-51, 2007.

3- HSU A.L., TANG P.F. and JAN M.H.: Analysis of impairments influencing gait velocity and asymmetry of hemi- plegic patients after mild to moderate stroke. Arch. Phys. Med. Rehabil., 84 (8): 1185-93, 2003.

4- KARTHIKBABU S., CHAKRAPANI M., GANESAN S. and ELLAJOSYULA R.: Relationship between Pelvic Alignment and Weight-bearing Asymmetry in Communitydwelling Chronic Stroke Survivors. J. Neurosci. Rural. Pract., 7 (Suppl 1): S37-S40, 2016.

5- VERHYDEN G., REUSEN C., GORRISON M., BRUMBY V., MORAN R., BURNETT M., et al.: Postural alignment is altered in people with chronic stroke and related to motor and functional performance. J. Neurol. Phys. Ther., 38 (4): 239-45, 2014.

6- KARTHIKBABU S., CHAKRAPANI M., GANESAN S. and ELLAJOSYLA R.: Pelvic alignment in standing and its relationship with trunk control and motor recovery of lower limb after stroke. J. Neurol. Clin. Neurosci., 5: 228, 2017.

7- JEONG H.S. and YOON J.K.: The effects of pelvic tilt exercise on balance of hemiplegic patients. J. Korean. Phys. Ther., 13: 41-8, 2006.

8- STASZKIEWICZ R., CHWAVA W., FORCZEK W. and LASKA J.: Three-dimensional analysis of the pelvic and hip mobility during gait on a treadmill and on the ground. Acta Bioeng and Biomech, 14 (2): 83-9, 2012.

9- VERHEYDEN G., VAN DUIJNHOVEN H.J., BURNETT M., LITTLEWOOD J., KUNKEL D. and ASHBURN A.M.: Kinematic analysis of head, trunk, and pelvis movement when people early after stroke reach sideways. Neurorehabil Neural Repair., 25 (7): 656-63, 2011.

10- CHUNG E.J., KIM J.H. and LEE B.H.: The effects of core stabilization exercise on dynamic balance and gait function in stroke patients. J. Phys. Ther. Sci., 25 (7): 803-6, 2013.

11- HAGINS M., BROWN M., COOK C., GSTALDER K., KAM M., KOMINER G., et al.: Intratester and intertester reliability of the palpation meter (PALM) in measuring pelvic position. J. Man. Manip. Ther., 6: 130-6, 1998.

12- RASMUSSEN-BARR E., NILSSON-WIKMAR L. and ARVIDSSON I.: Stabilizing training compared with manual treatment in sub-acute and chronic low-back pain. Man, Ther., 8 (4): 233-41, 2003.

13- HERRINGTON L.: Assessment of the degree of pelvic tilt within a normal asymptomatic population. Man. Ther. 16 (6): 646-8, 2011.

14-VRTOVEE T., JANSSEN M.M., LIKAR B., CASTELEIN R.M., VIERGEVER M.A. and PERNUS F.: A review of methods for evaluating the quantative parameters of sagittal pelvic alignment. Spine. J., 12 (5): 433-46, 2012.

15- BETTYYR. and JONATHAN A.: Essential medical statistics. ${ }^{2 n d}$ edition, Blackwell Publishing, pp. 102-17, 2003.

16- YU S.H. and PARK S.D.: The effects of core stability strength exercise on muscle activity and trunk impairment scale in stroke patients. J. Exerc. Rehabil., 9 (3): 362-7, 2013.

17-KONG S W., JEONG Y. and KIM J.Y.: Correlation between balance and gait according to pelvic displacement in stroke patients. J. Phys. Ther. Sci., 27: 2171-4, 2015. 
18- PARK B.S., KIM J.H., KIM M.Y., LEE L.K., YANG S.M., JEON H.J., et al.: Effect of a muscle strengthening exercise program for pelvic control on gait function of stroke patients. J. Phys. Ther. Sci., 27: 641-4, 2015.
19- LENNON S., ASHBURN A. and BAXTER D.: Gait outcome following outpatient physiotherapy based on the Bobath concept in people post stroke. Disabil. Rehabil., 28 (13-14): 873-81, 2006.

\section{تأثير تمرينات التحكم فى الحوض على المشى الدمافي فى مرضى السكتة الدماغية التوفية}

المشى غير الطبيعى واحد من أشهر المعوقات التى تتتج بعد حدوث السكتة الدماغية. تمرينات التحكم فى الصوض من الممكن أن تحسن

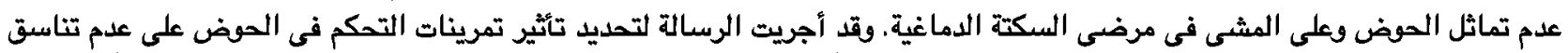

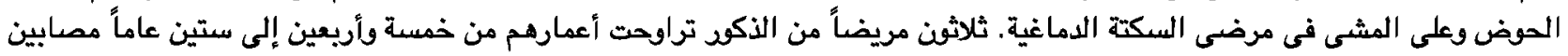

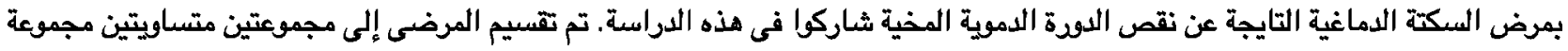

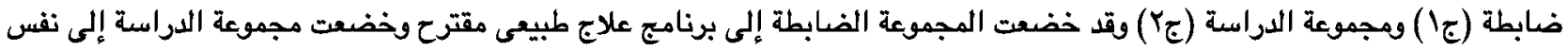

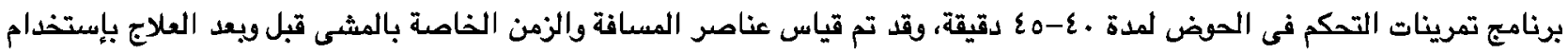

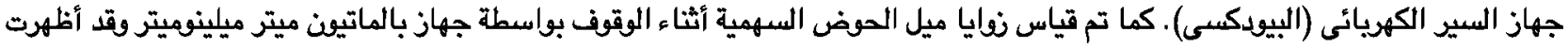
النتائج أن هنائ تحسن ملحوظ فى كل عناصر القياس ما عدا طول الخطوة على الجانب الغير مصاب في كلا المجموعتين. بالمقارنة بين كلا

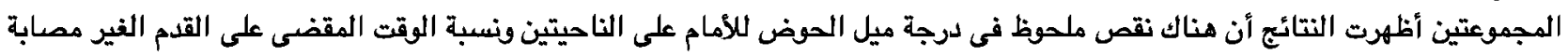

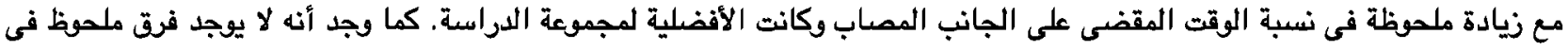
متويسط سرعة المشى بين المجموعتين. 